\title{
O Corpo Biológico e o Corpo Vestido no ensino da modelagem de vestuário
}

\author{
The Biological Body and The \\ Dressed Body in teaching \\ clothing patternmaking
}

Janaina Figueiredo Lorbieski ${ }^{[1]}$, Valdecir Babinski Júnior ${ }^{[2]}$, Dulce Maria Holanda Maciel[3], Lucas da Rosa[4], Icléia Silveira ${ }^{[5]}$

\begin{abstract}
Resumo: Por meio de uma revisão bibliográfica assistemática, este artigo tem como objetivo prescrever instrumentos e critérios acerca do ensino de modelagem que possam ser empregados para avaliar o desempenho de estudantes de moda em práticas pedagógicas cujo objeto central consiste no corpo dos usuários. Para tanto, a pesquisa apresenta dois eixos: (I) corpo biológico; e (II) corpo vestido. Como instrumentos, elencaram-se: (I) perfil antropométrico; e (II) lista de verificação de requisitos ergonômicos; entre outros. Quanto aos critérios de avaliação, destacaram-se: (I) a precisão de medidas tabeladas; e (II) a qualidade dos requisitos cumpridos; entre outros. Ademais, foram sugeridos pontos de partida para as práticas pedagógicas que envolvem o corpo como objeto de estudo no ensino de modelagem.
\end{abstract}

Palavras-chave: Modelagem de Vestuário. Ensino de Moda. Ensino de modelagem.

[1] Especialista em Empreendedorismo e Inovação para Startups, SENAI/SC-CTAI. jansfigueiredo@gmail.com

[2] Mestre em Design de Vestuário e Moda, UDESC. vj.babinski@gmail.com

[3] Doutora em Engenharia de Produção, UFSC. dulceholanda@gmail.com

[4] Doutor em Design, PUC-Rio. darosa.lucas@gmail.com

[5] Doutora em Design, PUC-Rio. icleiasilveira@gmail.com 
Abstract: Through an unsystematic literature review, this article aims to prescribe instruments and criteria about the teaching of patternmaking that can be used to assess the performance of fashion students in pedagogical practices whose central object is the body of the users. Therefore, the research presents two axes: (I) biological body; and (II) dressed body. The following instruments were listed: (I) anthropometric profile; and (II) ergonomic requirements checklist; between others. Among the evaluation criteria, the following stood out: (I) accuracy of tabulated measures; and (II) the quality of the requirements met; between others. Furthermore, starting points were suggested for pedagogical practices that involve the body as an object of study in teaching of patternmaking.

Keywords: Clothing Patternmaking. Fashion Teaching. Patternmaking Teaching.

\section{INTRODUÇÃO}

No processo de materialização do artefato vestível, estudantes de moda percorrem a jornada acadêmica da modelagem de vestuário. O produto esboçado pelos jovens designers, um conceito abstrato, ganha vida à medida que traços, retas, curvas e ângulos constroem as possibilidades do vestir com base em um corpo-suporte (ou busto-manequim) ou modelo de prova (ou modelo-manequim) (ROSA, 2005; SILVEIRA, 2017). Nishimura, Vergara e Gontijo (2017, p. 76) sustentam que “[...] a modelagem é de fato, se não a mais importante, uma etapa definitiva para o desenvolvimento de uma peça de roupa".

Rosa (2011, p. 53) afirma que "[...] na etapa de modelagem, com base no desenho técnico, o modelista interpreta as criações e elabora o molde, com procedimentos que permitem a planificação da anatomia do corpo humano [...]". Nesse processo de planificação, Silveira et al. (2018) citam que ocorre a viabilização da produção do vestuário em escala industrial. Para os autores, quando a tridimensionalidade do corpo está representada de maneira bidimensional no papel, pode-se executar o traçado dos moldes e escaloná-los. Por conseguinte, "os moldes, uma vez colocados sobre o tecido, cortados e unidos por costuras, resultarão nas peças de vestuário" (SILVEIRA et al., 2018, p. 554).

Entre os traços realizados no papel, o tecido drapeado sobre o manequim e as peças de vestuário confeccionadas, o estudante de moda aprende e apreende como vestir o corpo. Nesse fluxo de descoberta de pences, recortes, tomas, pregas e amarrações, o futuro designer conhece a modelagem plana (ou bidi- 
mensional) e a moulage (ou tridimensional), entre outras técnicas. Acerca do assunto, Souza e Pereira (2020, p. 18) sustentam que:

Dentro do que se instaurou como cânone para o ensino de modelagem, tanto em cursos técnicos e tecnológicos quanto em bacharelados, costuma-se abordar o ensino desta atividade por meio de duas técnicas distintas: a modelagem plana, geométrica ou bidimensional, e a moulage, também chamada de tridimensional ou draping [...].

O ensino da modelagem plana e da moulage reverbera não apenas na formação acadêmica do estudante de moda, mas também em seu desempenho no mercado de trabalho. Nesse sentido, Silveira et al. (2018, p. 564) citam que "os profissionais mais disputados pelas empresas do vestuário são os modelistas, por isso a formação, os conhecimentos e as habilidades destes profissionais são imprescindíveis às empresas do vestuário [...]". Os autores também apontam que o estado de Santa Catarina (SC) se encontra como o segundo maior polo educacional de cursos superiores na área de Moda no Brasil (BR) e que, nesses cursos, há presença de disciplinas voltadas para a modelagem de vestuário.

A exemplo do exposto, destacam-se os cursos superiores de Moda da Universidade do Estado de Santa Catarina (Udesc), do Instituto Federal de Santa Catarina (IFSC) e da Universidade do Extremo Sul Catarinense (Unesc) em parceria com o Serviço Nacional de Aprendizagem Industrial (Senai).

O curso de bacharelado em Moda da Udesc, em Florianópolis (SC), apresenta como disciplinas voltadas à modelagem de vestuário: (I) Modelagem do vestuário infantil e masculino ( $3^{\text {a }}$ fase); (II) Modelagem básica do vestuário feminino (4 fase); (III) Modelagem avançada do vestuário feminino (5a fase); (IV) Modelagem tridimensional - moulage (6 fase); (V) Modelagem do vestuário informatizada (7a fase); e (VI) Oficina de modelagem de vestuário ( $8^{\mathrm{a}}$ fase) (UDESC, 2021).

Já no curso superior de tecnologia em design de moda do campus de Jaraguá do Sul (SC) do IFSC, as unidades curriculares que abordam a modelagem de vestuário são: (I) 
Modelagem tridimensional ( $3^{\text {a }}$ fase); (II) Modelagem cartesiana (4 ${ }^{\text {a }}$ fase); (III) Princípios da modelagem computadorizada ( $5^{\text {a }}$ fase); e (IV) Modelagem computadorizada intermediária (optativa) (IFSC, 2018).

Por sua vez, no curso de tecnologia em design de moda da Unesc em pareceria com o Senai, na cidade de Criciúma (SC), são disciplinas que envolvem a modelagem de vestuário: (I) Introdução à modelagem do vestuário ( $2^{\mathrm{a}}$ fase); (II) Modelagem do vestuário I ( $3^{\text {a }}$ fase); (III) Modelagem do vestuário II (4 fase); (IV) Modelagem do vestuário III (5a fase); (V) Modelagem do vestuário informatizada ( $5^{\mathrm{a}}$ fase); e (VI) Modelagem do vestuário IV (6 $6^{\text {a }}$ fase) (UNESC, 2016).

Conforme descrito nos exemplos da Udesc, do IFSC e da Unesc, as disciplinas voltadas para a modelagem estão presentes em muitas fases dos cursos superiores de Moda. Nishimura, Vergara e Gontijo (2017) corroboram o observado e citam que, com facilidade, “[...] percebe-se a importância de uma disciplina como a modelagem e sua relevância para a formação profissional na área de moda [...]". Todavia, Souza e Pereira (2020, p. 13) revelam uma lacuna que oportuniza a proposição desse estudo: "a perspectiva da modelagem como ferramenta para o desenvolvimento das capacidades criativas ainda é pouco trabalhada no ambiente acadêmico [...]". De modo similar, Silveira et al. (2018, p. 565) citam que:

\footnotetext{
Vale a pena salientar que os cursos de moda do Estado de Santa Catarina não oferecem habilitação em modelagem, são geralmente voltados para o design de moda. As disciplinas de modelagem fazem parte da grade curricular destes cursos, não sendo, contudo, seu foco principal, mesmo sabendo que estes profissionais são os mais procurados pelas empresas do vestuário. Muitos alunos se tornam modelistas pelas oportunidades de trabalho que o mercado oferece.
}

Por sua vez, Heinrich (2005) e Silveira (2017) orientam que as disciplinas de modelagem sejam voltadas para o corpo, a fim de que, então, as capacidades técnica e criativa dos discentes possam ser desenvolvidas em alinhamento com 
o esperado pelo mercado de trabalho. Diante do exposto, o presente artigo tem como objetivo prescrever instrumentos e critérios acerca do ensino de modelagem que possam ser empregados para avaliar o desempenho de estudantes de moda em práticas pedagógicas cujo objeto central consiste no corpo dos usuários. Para tanto, empreendeu-se uma pesquisa bibliográfica de modo narrativo e assistemático.

Por fim, importa ressaltar que este artigo se estrutura a partir da fundamentação teórica que aborda a articulação entre o corpo, a modelagem e o vestuário em uma perspectiva educacional. Após serem expostas as dimensões do corpo biológico e do corpo vestido, procede-se para a discussão e para a sumarização dos argumentos explorados. Ao final do artigo, tecem-se considerações e sugestões para futuros estudos.

\section{O ENSINO DE MODELAGEM DE VESTUÁRIO EM SANTACATARINA (SC)}

O ensino da modelagem de vestuário no contexto de Santa Catarina (SC) apresenta-se marcado pelo cumprimento de roteiros pré-estabelecidos com sequências operacionais definidas e testadas de antemão por professores e técnicos laboratoriais (SILVEIRA, 2017; SILVEIRA et al., 2018).

lervolino (2014) menciona que, de modo geral, o conteúdo dessas disciplinas encontra-se pautado por apostilas compostas por um conjunto de ordens de execução e de tabelas de medidas próprias, que podem ser aplicadas tanto na modelagem bidimensional quanto na modelagem tridimensional. Para Souza e Pereira (2020), as disciplinas de modelagem encontram-se delineadas por seu caráter instrucional e pelo uso de peças pré-determinadas que podem ser confeccionadas com o objetivo de ilustrar os resultados a serem obtidos pelo estudante de moda.

Na visão de lervolino (2014) e Souza e Pereira (2020), esse estudante encontra empecilhos na aplicação técnica dos conhecimentos acerca da anatomia humana, uma vez que a modelagem de vestuário pode se apresentar como uma prá- 
tica complexa, rigorosa e de difícil assimilação. Nesse sentido, empiricamente, observa-se que a execução da sequência operacional prevista em apostilas de modelagem pode engessar a autonomia do estudante, em vez de descortinar o corpo como instrumento de ensino.

Além desses entraves, Santiago, Noronha e Zandomeneghi (2020) identificaram estudos acadêmicos que tratam do reconhecimento de problemas no processo de aprendizagem dos estudantes de moda nas disciplinas de modelagem, a saber: (I) Menezes e Spaine (2010); Silva e França (2018); Lima et al. (2019); e Araújo, Souza e Filgueiras (2019), demonstrados no Quadro 1.

Quadro 1-Obras e problemas identificados na literatura investigada por Santiago, Noronha e Zandomeneghi (2020)

\begin{tabular}{|l|l|}
\hline Obra & Problema identificado \\
\hline $\begin{array}{l}\text { Dificuldade na aplicação de conceitos } \\
\text { acerca da ergonomia e da antropometria no } \\
\text { desenvolvimento de moldes, bem como falta } \\
\text { de preocupação com o corpo dos usuários. }\end{array}$ \\
\hline $\begin{array}{l}\text { Spaine (2010) } \\
\text { Debilidade no uso de conhecimentos } \\
\text { sobre geometria antes do ensino } \\
\text { sobre o traçado do molde. }\end{array}$ \\
\hline \begin{tabular}{l} 
Ausência de conhecimentos prévios. \\
\hline Silva e França
\end{tabular} & \begin{tabular}{l} 
Falta de motivação. \\
\hline (2018)
\end{tabular} \\
\hline Baixa carga horária da disciplina. \\
\hline Condições inadequadas de laboratórios \\
\hline e acesso deficitário a tecnologias.
\end{tabular}




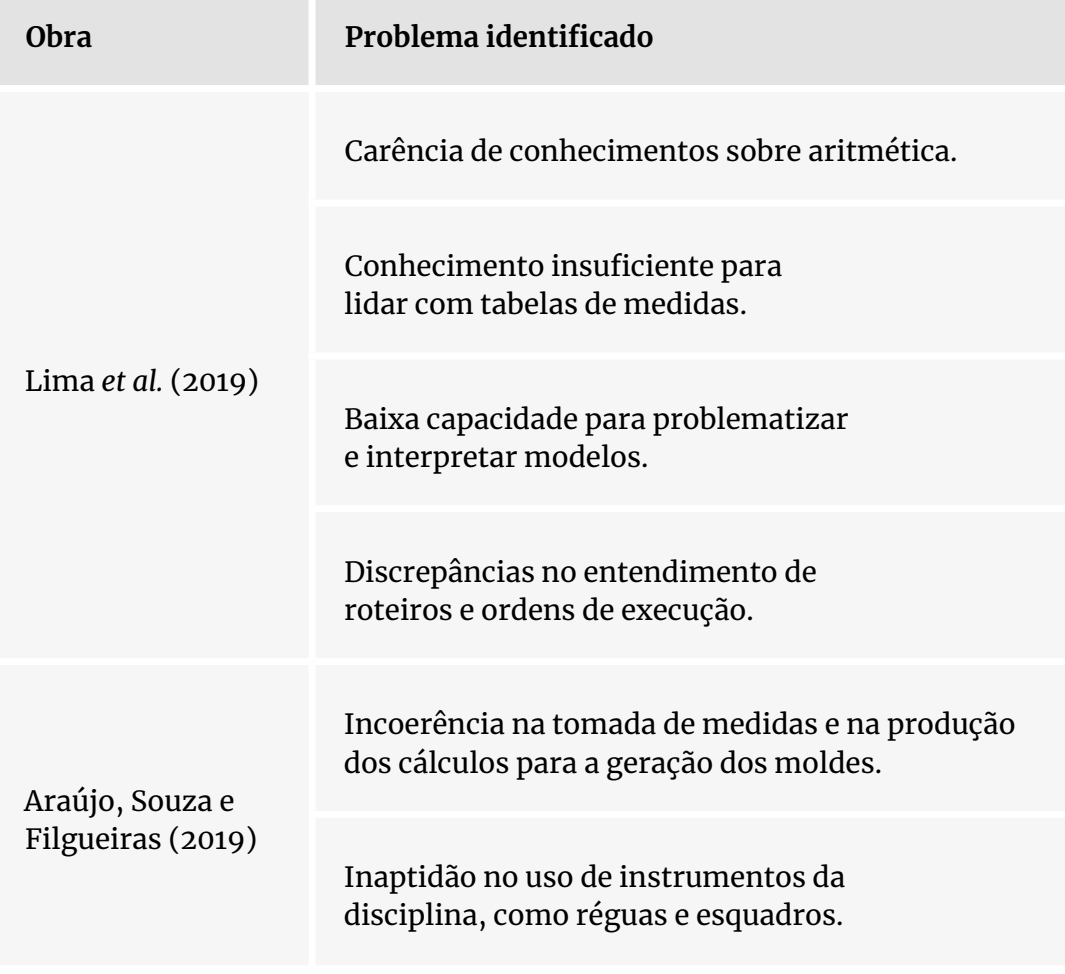

Fonte: adaptado de Santiago, Noronha e Zandomeneghi (2020, p. 96-97).

Como observa-se no levantamento de Santiago, Noronha e Zandomeneghi (2020), as disciplinas de modelagem do vestuário apresentam bloqueios aos estudantes de moda que perpassam a compreensão de conceitos teóricos e matemáticos e se estendem até o uso inadequado de ferramentas, instrumentos e espaços laboratoriais. Por sua vez, ao identificar empecilhos similares, lervolino (2014) cita que um ensino de modelagem deficitário pode resultar em um profissional inapto a transformar informações de ordem estética por meio do domínio técnico e da criatividade em moldes para vestir um corpo-suporte.

Silveira et al. (2018) acrescentam que, além de uma formação acadêmica apropriada e estimuladora, o futuro profissional de modelagem também deve ser orientado por experiências práticas e mercadológicas que propiciem o avanço de suas competências e a lapidação de suas habilidades. Para as 
autoras, "a formação profissional deve promover, aos indivíduos, conhecimentos mais amplos para as atividades tecnicamente mais complexas, de maneira a proporcionar a capacidade de aprender, avaliar, criticar, propor e tomar decisões [...]" (SILVEIRA et al., 2018, p. 565).

Rosa (2011) sustenta os profissionais de modelagem podem ser compreendidos em dois grupos: (I) modelistas sob medida; e (II) modelistas industriais. Conforme o autor, cada grupo apresenta um comportamento diferente em relação ao corpo dos usuários:

Enquanto o modelista sob medida trabalha com medidas que tirou de alguém para quem vai realizar o molde, o modelista industrial trabalha com padrões prédeterminados, utilizando tabelas que se enquadram ao padrão de medidas do corpo humano, seguindo uma numeração já determinada. Com esta numeração padrão, são desenvolvidas as demais numerações, sejam maiores ou menores (ROSA, 2011, p. 52).

Em consonância com Rosa (2011), Silveira et al. (2018) compreendem que, para que modelistas sob medida e industriais possam ser autônomos na solução de problemas, eles devem ter domínio sobre as seguintes unidades de conhecimento:

- Interpretação da representação gráfica das peças de vestuário propostas por designers/estilistas;

- Identificação de tecidos, aviamentos e aplicações, bem como conhecer suas propriedades físicas e mecânicas;

- Manejo dos fatores técnicos e funcionais e das qualidades ergonômicas e antropométricas das peças, com vistas à criação de diagramas passíveis de produção em escala industrial; 
- Desenvolvimento da modelagem das peças sob as técnicas seguidas pela empresa, sejam elas bidimensionais ou tridimensionais;

- Competência para operar sistemas auxiliados por computador;

- Visão global dos processos e das etapas relacionadas com a produção da coleção de vestuário;

- Domínio do preenchimento da ficha técnica de vestuário, com o objetivo de detalhar materiais, fornecedores, consumo e esquemas de montagem das peças;

- Habilidade de, se necessário, realizar os protótipos das peças que foram modeladas;

- Percepção para identificar quais os tipos de máquinas e os aparelhos necessários para a preparação e a costura das peças;

- Compreensão de que os conhecimentos adquiridos na rotina de trabalho devem ser compartilhados com os demais profissionais envolvidos no processo produtivo.

Para Silveira et al. (2018), os atributos supramencionados correspondem a unidades de conhecimento que refletem a formação acadêmica e profissional tradicional que o estudante de moda deve acumular no âmbito da modelagem. Para que haja uma superação do lugar-comum, sugere-se que o corpo seja considerado o eixo central das práticas previstas nas unidades de conhecimento das disciplinas de modelagem. Esse conceito será explorado com maior afinco no próximo tópico deste artigo. 


\section{O CORPO NO ENSINO DA MODELAGEM}

Na relação com o vestir, o corpo pode ser considerado o princípio e o fim no desenvolvimento e na confecção de peças de vestuário. Silveira et al. (2013, p. 5) corroboram com esse pensamento e citam que "para trabalhar com vestuário, é necessário conhecer a anatomia do corpo humano, para representá-lo no traçado bidimensional (modelagem plana) ou criar sobre ele modelos de vestuário (modelagem tridimensional)". Por sua vez, Carvalho (2011, p. 8) afirma que "a roupa é um invólucro para o corpo. Portanto, ao ser modelada a peça deve respeitar a estrutura física e suas articulações, pois corpo e roupa devem movimentar-se no mesmo ritmo [...]".

Grave (2010) sustenta que o vestuário pode ser considerado responsável por permitir ao seu usuário a interatividade necessária para sua socialização com o coletivo e com o seu contorno imediato, assim como pode ser visto como uma extensão do próprio corpo, uma vez que ele possibilita a execução de ações e de movimentos de forma confortável e eficiente. Nessa perspectiva, a modelagem de vestuário como campo do conhecimento se ocupa da estrutura e da arquitetura do vestir e possibilita transpor a morfologia da anatomia corporal para a construção da sintaxe da forma (FREITAS, 2004; HEINRICH, 2005; GRAVE, 2010; SANCHES, 2016). Acerca do assunto, Sanches (2016, p. 15) declara que:

Na experiência de uso, o vestuário de moda constitui a interface entre corpo e contexto, na qual os vínculos estabelecidos podem ser muito estreitos e imediatos. Em uma relação simbiótica, a veste se incorpora ao sujeito, como segunda pele, e participa das trocas com o entorno, em nível individual e coletivo [...].

Para Sanches (2016), o vestuário consiste no primeiro espaço habitado pelo corpo e, portanto, instrumentaliza-o para circular em outros envoltórios espaciais. Por sua vez, o corpo passa a ser portador de determinada expressão individual e a desempenhar dado papel social. Segundo a autora, nessa dinâmica, "[...] o vestuário de moda é percebido como por- 
tador de informações que, atreladas à linguagem corporal, criam um enunciado conexo [...]" (SANCHES, 2016, p. 15).

Sanches (2016) sustenta, também, que quando um corpo vestido se encontra com outros corpos vestidos, forma-se uma malha comunicativa que possibilita a produção de sentidos entre corpos habitantes e corpos habitados. Importa sublinhar que, na perspectiva da autora, pode-se compreender que o corpo habitante corresponde ao corpo biológico do usuário e o corpo habitado ao corpo vestido.

Castilho (2004) e Silveira (2017) consideram que o corpo vestido representa o resultado obtido em um processo de desenvolvimento de peças de vestuário. Para ambas, a ação de vestir tem o início marcado pela observação do corpo e seu respectivo mapeamento e a conclusão acontece diante da aprovação do corpo quanto à peça quando esta passa a ser avaliada por intermédio de um modelo de prova.

Nesse mapeamento, Castilho (2004) assevera que o corpo biológico - também chamado de corpo anatômico deve ser compreendido a partir de suas proporções e de seus componentes formais, que, quando concebidos por meio de variáveis verticais e horizontais, permitem alcançar e revelar determinada anatomia plástica. Para a autora, essas variáveis devem tomar partido das características topológicas do corpo biológico, isto é, devem considerar altura, volume e proporção.

Para complementar, Souza e Pereira (2020, p. 27) defendem "[...] o uso de meios de sensibilização dos estudantes para o corpo e a diversidade de olhares sobre sua relação com o vestir". Portanto, para as autoras, o corpo, como instrumento para sensibilização no ensino de modelagem de vestuário, pode fornecer subsídio para a valorização das subjetividades produzidas acerca do vestir, de quem veste e do que é vestido. As autoras acreditam que considerar o corpo sensível pode subjugar o automatismo e a tecnicidade das técnicas convencionais.

Assim, com base no pressuposto do corpo como eixo central nas unidades de conhecimento das disciplinas de modelagem 
de vestuário como meio para mitigar as lacunas descritas anteriormente na aprendizagem de futuros modelistas, explora-se a seguir as dimensões do corpo biológico e do corpo vestido.

\section{CORPO BIOLÓGICO, ANATÔMICO OU HABITANTE}

O corpo biológico se revela pelo esqueleto, pelos órgãos e pelos músculos que propiciam sustentação e movimentação para o usuário de vestuário. Esse corpo encontra-se dividido em membros superiores, que podem ser dotados de determinada combinação de movimentos, e membros inferiores, sobre os quais está apoiado o peso do indivíduo (HEINRICH, 2005; DANGELO; FATTINI, 2008; CARVALHO, 2011).

Com base na diferença entre a altura, a concentração de gordura e o tamanho de membros superiores e inferiores, entre outros aspectos físicos, o psicólogo estadunidense William Herbert Sheldon Jr. desenvolveu a teoria somatótipa, que estabelece três tipos físicos de corpos biológicos: (I) o corpo ectomorfo, que apresenta como característica marcante a magreza; (II) o corpo mesomorfo, cuja musculosidade se sobressai às demais características físicas; e (III) o corpo endomorfo, que pode ser compreendido pela adiposidade em demasia (IIDA, 2005).

O levantamento antropométrico realizado por Sheldon Jr. data da década de 1940 e envolveu mais de 4.000 estudantes norte-americanos. Apesar de críticas por parte da comunidade acadêmica internacional, que alega falta de cientificidade na teoria somatótipa, as contribuições de Sheldon Jr. permitiram avanços na visualização e na compreensão do corpo biológico. A partir de então, conceitos como antimeria ${ }^{[6]}$, metameria ${ }^{[7]}$, estratigrafia ${ }^{[8]}$ e paquimeria ${ }^{\left[{ }^{[9]}\right.}$ passaram a figurar em estudos do campo da ergonomia (IIDA, 2005).

Cabe sublinhar que, segundo observam Freitas (2004), Dangelo e Fattini (2008) e Carvalho (2011), se investigados os antímeros do corpo biológico, faz-se possível perceber que todos os usuários têm determinado grau de assimetria, que se manifesta tanto no exterior quanto nos limites internos
[6] A antimeria ocupa-se do estudo do corpo biológico por intermédio de sua simetria.

[7] A metameria considera o corpo biológico como sendo formado pela repetição de segmentos que podem ser fragmentados para estudo.

[8] A estratigrafia trata da visualização do corpo biológico por meio de camadas.

[9] A paquimeria considera a formação do corpo biológico a partir dos tubos neural e visceral. 
do corpo humano. Todavia, para efeito de estudo acadêmico e de produção industrial, o corpo biológico tem sido considerado como simétrico e há desprezo em relação à teoria somatótipa (ROSA, 2005; 2011; CARVALHO, 2011; SILVEIRA et al., 2013; SILVEIRA, 2017).

Nesse sentido, Souza e Pereira (2020, p. 23-24) comentam que "[...] os materiais didáticos de modelagem do vestuário não contemplam traçados, interpretações ou estímulo ao desenvolvimento de modelos para diferentes tipos de corpos [...]". Por observação empírica, percebe-se que, como consequência da desconsideração à diversidade de corpos, a modelagem de vestuário pode produzir anomalias no vestir, a exemplo de golas que não se ajustam ao pescoço do usuário, cavas que limitam movimentos rotineiros ou mangas excessivamente longas. Nesse sentido, Poci, Carvalho e Cunha (2016, p. 1) afirmam que:

É sabido que os produtos de vestuário, disponíveis no mercado brasileiro, nem sempre atendem às necessidades do cliente. Essa relação, vestuário/usuário, encontrase prejudicada devido às medidas das peças não corresponderem às dos consumidores. Podemos citar, por exemplo, as discrepâncias entre manequins de uma mesma loja e de lojas diferentes, os comprimentos em excesso nas calças e nas mangas de camisas e casacos, a altura inadequada de algumas calças de cós baixo, etc [...].

Acredita-se que esses problemas estejam vinculados com a padronização de tabelas de medidas que criam corpos irreais no momento da planificação geométrica de corpos biológicos sob a intenção de alcançar tamanhos médios. Souza e Pereira (2020) corroboram com o observado e citam que isso ocorre em função da substituição da diversidade de corpos pelo uso de um tamanho mediano único, com medidas proporcionais entre os membros, a exemplo do tamanho $\mathrm{n}^{\circ} 42$ para o corpo feminino. Nesse contexto, Silveira et al. (2018, p. 554) esclarecem que, 
A modelagem é trabalhada com padrões determinados, sendo necessário, portanto, utilizar-se de tabelas de medidas que se assemelham ao padrão médio do corpo, dentro de uma numeração pré-estabelecida. O padrão médio brasileiro para o corpo feminino é o manequim $\mathrm{n}^{\circ} 42$, enquanto que para o corpo masculino é o $\mathrm{n}^{\mathrm{0}} 3$, sendo ambos correspondentes ao tamanho médio. Para executar a modelagem do protótipo, adotam-se estes dois tamanhos principalmente pela facilidade de poder testar em pessoas que possuam as medidas aproximadas, favorecendo posteriormente a graduação dos moldes.

Diante disso, o uso de medidas medianas não consiste, por si só, em um problema de modelagem. Quando essas medidas passam a ser adotadas como um padrão para uma amostra expressiva de usuários, há sim possibilidade de surgirem deformações nas peças de vestuário com menores e com maiores proporções. Como forma de atenuar essas diferenças, sugere-se que o ensino de modelagem seja orientado para o emprego de medidas medianas no contexto de nichos de usuários que, por sua vez, podem ser agrupados com base em semelhanças físicas.

Ao se debruçar sobre a obra de lida (2005), Carvalho (2011) orienta, também, que o ensino de modelagem deve considerar a construção do perfil antropométrico dos usuários com base em meios diretos e indiretos. Os meios diretos estão relacionados com ferramentas que podem entrar em contato físico com o corpo biológico, tais como fitas métricas, trenas, réguas, paquímetros ou similares. Já os meios indiretos tratam do emprego de fotografias do corpo, que podem ser analisadas a fim de se estabelecerem medidas e proporções anatômicas.

Nesse sentido, Carvalho (2011) indica que as medidas do corpo biológico podem ser tomadas por meio de três perspectivas: (I) da antropometria estática, que se refere às dimensões do corpo em repouso ou parado; (II) da antropometria dinâmica, que investiga o alcance dos movimentos dos usuários; e (III) da antropometria funcional, que trata das medidas aferidas sob a execução de determinadas tarefas. 
Segundo a autora, depois de tomadas as medidas necessárias para a modelagem das peças de vestuário, deve-se considerar as variáveis antropométricas que correspondem aos comprimentos e aos perímetros.

Carvalho (2011, p. 2) ressalta que "o processo de modelagem exige do profissional uma série de conhecimentos sobre as medidas do corpo humano e como o mesmo se movimenta [...]". Isso permite inferir que, além do perfil antropométrico, o principal instrumento de avaliação acerca do corpo biológico no ensino de modelagem consiste na tabela de medidas, que deve ser elaborada pelos estudantes de moda com atenção e precisão. Nesse sentido, Olivete, Pereira e Arruda (2010, p. 9) citam que "o fator mais importante no desenvolvimento da modelagem é a exatidão das medidas, pois delas dependem a perfeição do molde, a vestibilidade da roupa, além da economia de tempo na execução, prova e ajustes".

Logo, no ensino de modelagem, o corpo biológico pode ser avaliado por meio de atividades e práticas que concentrem esforços na elaboração de uma tabela de medidas medianas precisas, apuradas e adequadas ao nicho de usuário que se pretende atender. Ademais, deve-se considerar traçar o perfil antropométrico do usuário por meio das dimensões estática, dinâmica e funcional. A seguir, procede-se para a descrição do corpo vestido e de seus respectivos instrumentos de avaliação.

\section{CORPO VESTIDO, SENSÍVEL OU HABITADO}

Na perspectiva do corpo vestido ocorre o transporte das medidas medianas observadas no corpo biológico para necessidades e requisitos de projeto com foco na ergonomia do vestuário. Nesse contexto, Souza e Pereira (2020, p. 19) comentam que, para o ensino da modelagem:

[...] são necessários cálculos de execução e conhecimentos sobre o corpo humano, como também conhecimentos sobre os aspectos ergonômicos que envolvem a construção e o equilíbrio do corpo e como o mesmo se "comportará" perante o caimento, as texturas e os volumes dos modelos propostos. 
O conhecimento sobre a ergonomia do vestuário também é citado por Silveira et al. (2013) como fundamental aos estudantes de moda. Os autores mencionam que os futuros profissionais de modelagem devem estar atentos para os seguintes requisitos ergonômicos: (I) segurança; (II) proteção; (III) mobilidade; (VI) adequação estética; e (V) conforto. Sobre esse último requisito, Nicolini (1995) apresenta três perspectivas: (I) o conforto físico, relacionado com as sensações provocadas pelo contato dos materiais com o corpo dos usuários, quer seja em posições estáticas ou em movimento; (II) o conforto psicológico, que diz respeito à estética dos produtos e aos valores simbólicos a eles aferidos; e (III) o conforto fisiológico, que se configura a partir da dimensão das propriedades térmica e hidrodinâmica dos materiais com relação às necessidades metabólicas dos usuários.

Nishimura, Vergara e Gontijo (2017, p. 77) ressaltam que, apesar dos requisitos ergonômicos serem constantemente mencionados por profissionais, professores e estudantes de modelagem, "[...] muito produto do vestuário ainda carece de características ergonômicas. Isso é reflexo de um ensino incipiente da disciplina". Essa defasagem também foi observada por Mello (2011), que define como requisitos ergonômicos: (I) a qualidade técnica; (II) a qualidade ergonômica; e (III) a qualidade estética. Para o autor, o primeiro requisito visa a mensurar a eficiência das peças de vestuário mediante a finalidade para a qual foram concebidas. Por sua vez, o segundo requisito trata da interação entre as peças e o corpo dos usuários. Por fim, a qualidade estética envolve a satisfação sensorial dos usuários enquanto vestem as peças projetadas - o que envolve a sensibilização do corpo por intermédio do vestuário.

Para assegurar o atendimento aos requisitos ergonômicos, Rosa (2005; 2011), Silveira et al. (2013; 2018), lervolino (2014), Lima e Italiano (2016), Silveira (2017) e Santiago, Noronha e Zandomeneghi (2020) afirmam que os estudantes de moda podem ser apresentados a duas técnicas construtivas de modelagem: (I) modelagem plana; e (II) moulage. As vanta- 
gens do uso da modelagem plana residem na possibilidade de replicação dos moldes gerados em escalas industriais. A exemplo disso, cita-se que um único molde básico de calças jeans pode ser empregado em várias coleções diferentes e ser graduado para tamanhos diversos. A técnica também permite que o traçado de moldes seja desenhado de maneira manual ou de modo assistido por computador.

Silveira et al. (2013) e Lima e Italiano (2016) destacam como vantagens do emprego da técnica de moulage: (I) a estimulação do uso criativo das formas e dos volumes tridimensionais; (II) o favorecimento à visualização imediata das formas e suas possibilidades estéticas; (III) o provimento à praticidade e à funcionalidade do vestuário, uma vez que se tornam possíveis testes práticos de vestibilidade; (IV) a observação imediata do conjunto e das partes que compõem a peça de vestuário; $(V)$ a construção da peça na totalidade de sua tridimensionalidade (frente, costas e lateral); (VI) o desenho ergonômico da peça, com ajustes precisos; e (VII) a oportunidade de avaliar, antes da peça estar confeccionada, a inserção de elementos decorativos e outros ornamentos para adequações estilísticas.

Além das vantagens supramencionadas, Silveira et al. (2013) sublinham que a moulage pode permitir ao estudante de modelagem a precisão da localização de pences e de recortes, assim como detalhes de modelo (a exemplo de fendas e nesgas), mediante a manipulação das linhas estruturais do corpo. Independentemente da técnica construtiva adotada, acredita-se que os resultados obtidos pelos estudantes, se considerados os requisitos ergonômicos mediante o traçado dos moldes, para além do cumprimento de uma sequência operacional pré-determinada, podem sobrepujar soluções pasteurizadas e insípidas que provocariam, de outro modo, problemas para usuários e empresas.

Assim, considera-se que o corpo vestido no ensino de modelagem está relacionado com as competências técnicas para o desenvolvimento de moldes que atendam às neces- 
sidades ergonômicas e de qualidade dos usuários. Portanto, como instrumentos de avaliação, podem-se empregar uma lista de verificação de requisitos que devem ser cumpridos e testados, posteriormente, por meio de protótipos. A seguir, descrevem-se os procedimentos metodológicos empregados nesta pesquisa.

\section{PROCEDIMENTOS METODOLÓGICOS}

Mediante a classificação científica proposta por Gil (2008), este artigo se enquadra como: (I) pesquisa qualitativa, acerca de sua abordagem ao problema de pesquisa; (II) pesquisa descritiva, quanto à construção de seu corpo de conhecimento e de seu objetivo; e (III) pesquisa básica, do ponto de vista de sua finalidade.

Como instrumento de coleta de dados, o artigo emprega o levantamento bibliográfico com base em uma revisão narrativa e assistemática. Portanto, cabe sublinhar que a seleção das obras que compuseram a fundamentação teórica foi realizada por intermédio da técnica snowball sampling (amostragem "bola de neve"), com início nas referências bibliográficas encontradas em Rosa (2005; 2011) e Silveira (2017).

O tratamento das informações coletadas foi subsidiado por uma postura epistêmica interpretativista com inclinações ao pensamento indutivo, o que permitiu aos autores traçarem generalizações a partir dos achados acadêmicos. Desse modo, a seguir, apresenta-se o resultado da pesquisa.

\section{RESULTADO}

Conforme visto na literatura empregada neste artigo, se o ensino de modelagem de vestuário assumir uma forma de repetição mecânica e, tão somente, estiver baseada no raciocínio lógico do pensamento cartesiano, as possibilidades de inovação e de sensibilização por parte dos estudantes podem ser diminuídas - o que poderá prover, em breve, profissionais criativamente atrofiados (IERVOLINO, 2014; SANTIAGO; NORONHA; ZANDOMENEGHI, 2020). 


\begin{abstract}
A partir dessa observação, elaborou-se o Quadro 2, que apresenta os resultados objetivados por meio de três categorias separadas em dois eixos (corpo biológico e corpo vestido): (I) ponto de partida para práticas pedagógicas; (II) instrumentos de avaliação recomendados; e (III) critérios de avaliação sugeridos.
\end{abstract}

Quadro 2-O corpo biológico e o corpo vestido no ensino de modelagem

\begin{tabular}{|c|c|c|c|}
\hline \multirow[b]{2}{*}{ Eixo } & \multicolumn{3}{|c|}{ Ensino de modelagem } \\
\hline & $\begin{array}{l}\text { Ponto de partida para } \\
\text { práticas pedagógicas }\end{array}$ & $\begin{array}{l}\text { Instrumentos } \\
\text { de avaliação } \\
\text { recomendados }\end{array}$ & $\begin{array}{l}\text { Critérios de avaliação } \\
\text { sugeridos }\end{array}$ \\
\hline $\begin{array}{l}\text { Corpo biológico, } \\
\text { anatômico ou } \\
\text { habitante }\end{array}$ & $\begin{array}{l}\text { - Captura das medidas } \\
\text { antropométricas estática, } \\
\text { dinâmica e funcional; } \\
\text { - Teoria somatótipa: } \\
\text { corpos endomorfo, } \\
\text { ectomorfo e mesomorfo. }\end{array}$ & $\begin{array}{l}\text { - Tabela de medidas } \\
\text { medianas para } \\
\text { nichos de usuários; } \\
\text { - Perfil antropométrico } \\
\text { obtido por meio } \\
\text { direto e indireto. }\end{array}$ & $\begin{array}{l}\text { - Precisão das } \\
\text { medidas tabeladas; } \\
\text { - Rigor na coleta } \\
\text { de medidas; } \\
\text { - Amostragem do } \\
\text { nicho de usuários; } \\
\text { - Coerência do perfil } \\
\text { antropométrico } \\
\text { estabelecido. }\end{array}$ \\
\hline $\begin{array}{l}\text { Corpo vestido, } \\
\text { sensível ou habitado }\end{array}$ & $\begin{array}{l}\text { - Dimensões do conforto: } \\
\text { físico, psicológico } \\
\text { e fisiológico; } \\
\text { - Requisitos da } \\
\text { qualidade: técnica, } \\
\text { ergonômica e estética; } \\
\text { - Técnicas construtivas: } \\
\text { modelagem plana } \\
\text { e moulage. }\end{array}$ & $\begin{array}{l}\text { - Lista de verificação de } \\
\text { requisitos ergonômicos } \\
\text { em termos de } \\
\text { segurança, proteção, } \\
\text { mobilidade, adequação } \\
\text { estética e conforto; } \\
\text { - Protótipo físico } \\
\text { em escala real. }\end{array}$ & $\begin{array}{l}\text { - Caimento do } \\
\text { protótipo produzido; } \\
\text { - Volumetria do } \\
\text { protótipo conforme a } \\
\text { intenção do estudante; } \\
\text { - Qualidade dos } \\
\text { requisitos cumpridos; } \\
\text { - Rigor no desenho } \\
\text { das linhas estruturais } \\
\text { do corpo; } \\
\text { - Competência técnica } \\
\text { no traçado dos moldes. }\end{array}$ \\
\hline
\end{tabular}

Fonte: elaborado pelos autores (2021). 
Conforme observado, o Quadro 2 apresenta recomendações para o ensino de modelagem que podem ou não ser utilizadas por professores para mensurar o resultado obtido por estudantes de moda em práticas pedagógicas. Importa comentar que o quadro encontra limitações ao abordar a dinâmica de avaliação com base em achados teóricos. Portanto, para futuros estudos, recomenda-se que o quadro seja aplicado em aulas laboratoriais com a finalidade de se testarem os pressupostos traçados, independentemente da categoria. Apresentado o resultado da pesquisa, procede-se às considerações finais.

\section{CONSIDERAÇÕES FINAIS}

Esta pesquisa teve como objetivo prescrever instrumentos e critérios acerca do ensino de modelagem que possam ser empregados para avaliar o desempenho de estudantes de moda em práticas pedagógicas cujo objeto central consiste no corpo dos usuários. Para tanto, estabeleceu-se como pressuposto a compreensão de dois eixos disciplinares: (I) o corpo biológico; e (II) o corpo vestido. Sobre o primeiro, como instrumentos de avaliação elencaram-se: (I) tabela de medidas medianas para nichos de usuários; e (II) perfil antropométrico obtido por meio direto e indireto. Como critérios, citam-se: (I) precisão das medidas tabeladas; (II) rigor na coleta de medidas; (III) amostragem do nicho de usuários; e (IV) coerência do perfil antropométrico estabelecido.

No segundo eixo, os instrumentos de avaliação foram definidos como: (I) lista de verificação de requisitos ergonômicos em termos de segurança, proteção, mobilidade, adequação estética e conforto; e (II) protótipo físico em escala real. Como critérios para avaliar os resultados obtidos, estabeleceu-se: (I) caimento do protótipo produzido; (II) volumetria do protótipo conforme a intenção do estudante; (III) qualidade dos requisitos cumpridos; (IV) rigor no desenho das linhas estruturais do corpo; e (V) competência técnica no traçado dos moldes. 
Ademais, a pesquisa também apontou o ponto de partida para a realização de tais práticas pedagógicas. Acerca do corpo biológico, sugere-se: (I) a captura das medidas antropométricas estática, dinâmica e funcional; e (II) a teoria somatótipa: corpos endomorfo, ectomorfo e mesomorfo. Sobre o corpo vestido, recomenda-se: (I) as dimensões do conforto: físico, psicológico e fisiológico; (II) os requisitos da qualidade: técnica, ergonômica e estética; e (III) as técnicas construtivas: modelagem plana e moulage.

Assim, o resultado obtido com base na literatura consultada constitui a principal contribuição desta pesquisa, bem como sustenta a proposição de Sanches (2016) na classificação do corpo no âmbito da modelagem de vestuário (corpo habitante versus corpo habitado) ao adicionar novas camadas teóricas (corpo biológico versus corpo vestido e corpo anatômico versus corpo sensível). Ainda, faz-se necessário agradecer o apoio institucional recebido por parte do Centro de Artes (Ceart) e do Programa de Pós-Graduação em Design de Vestuário e Moda (PPGModa) da Universidade do Estado de Santa Catarina (Udesc), sem os quais essa pesquisa não existiria. Por fim, os autores do artigo encorajam professores e estudantes a continuarem suas jornadas no ensino da modelagem de vestuário de modo criativo, reflexivo, crítico e ético. 


\section{REFERÊNCIAS BIBLIOGRÁFICAS}

ARAÚJO, Maria do Socorro de; SOUZA, Walkíria Guedes de; FILGUEIRAS, Araguacy Paixão Almeida. Experimento metodológico para o processo de ensino-aprendizagem da modelagem plana feminina: praxis docente $x$ discente no curso de design-moda-UFC. Revista de Ensino em Artes, Moda e Design, Florianópolis, v. 3, n. 2, p. 41-52, 10 jul. 2019. Disponível em: https:// bit.ly/3CMvwbB. Acesso em: 15 ago. 2021.

CARVALHO, Maria Helena Ribeiro de. Ergonomia e Modelagem: a função da modelista perante o corpo. In: COLÓQUIO DE MODA, 7., 2011, Maringá. Anais [...]. Maringá: [S.I], 2011. p. 1-10. Disponível em: https://bit.ly/362A6Ew. Acesso em: 08 out. 2020.

CASTILHO, Kathia. Moda e linguagem. São

Paulo: Anhembi Morumbi, 2004.

DANGELO, José Geraldo; FATTINI, Carlo Américo. Anatomia humana básica. 2. ed. São Paulo: Atheneu, 2008.

FREITAS, Valdemar. Anatomia: conceitos e fundamentos. Porto Alegre: Artmed, 2004.

GIL, Antônio Carlos. Métodos e técnicas de pesquisa social. 6. ed. São Paulo: Atlas, 2008.

GRAVE, Maria de Fátima. Modelagem tridimensional ergonômica. São Paulo: Escrituras, 2010.

HEINRICH, Daiane Pletsch. Modelagem e técnica de interpretação para confecção industrial. Novo Hamburgo: FEEVALE, 2005. 
IERVOLINO, Fernanda. 41 anos de estudos de modelagem do vestuário: uma proposta de aperfeiçoamento do ensino de modelagem através da usabilidade. 2014. 104 f. Dissertação (Mestrado) - Curso de Pós-Graduação em Design, Universidade do Estado de Santa Catarina, Florianópolis, 2014.

IFSC - Instituto Federal de Santa Catarina. Projeto Pedagógico de Curso Superior: Curso Superior de Tecnologia em Design de Moda. Jaraguá do Sul: IFSC, 2018.

Disponível em: https://bit.ly/3IVMr4y. Acesso em: 23 jul. 2021.

IIDA, Itiro. Ergonomia: projeto e produção. 2. ed. rev. e ampl. São Paulo: Edgar Blucher, 2005.

LIMA, Jonathan Gurgel de; ITALIANO, Isabel Cristina. O ensino do design de moda: o uso da moulage como ferramenta pedagógica. Educação e Pesquisa, São Paulo, v. 42, n. 2, p.477-490, jun. 2016. Disponível em: https://bit.ly/35iWoBa. Acesso em: 05 maio 2018.

LIMA, Márcio Soares et al. A modelagem por trás dos moldes: experiências em sala de aula. Revista de Ensino em Artes, Moda e Design, Florianópolis, v. 3, n. 1, p. 113-122, 22 fev. 2019. Disponível em: https://bit.ly/3zKJFnR. Acesso em: 17 ago. 2019.

MELLO, Willyams Bezerra de. Proposta de um método aberto de projeto de produto: três alternativas de criação. 2011. 157 f. Dissertação (Mestrado) - Curso de PósGraduação em Engenharia de Construção Civil e Urbana, Universidade de São Paulo, São Paulo, 2011. Disponível em: http://bit.ly/3f2xCM0. Acesso em: 03 mar. 2020. 
MENEZES, Marizilda dos Santos; SPAINE, Patrícia Aparecida de Almeida. Modelagem Plana Industrial do Vestuário: diretrizes para a indústria do vestuário e o ensino-aprendizado. Projética, Londrina, v. 1, n. 1, p. 82-100, dez. 2010. Disponível em: https:// bit.ly/3oaXutl. Acesso em: 17 ago. 2021.

NICOLINI, Rubens. Medida de conforto em

Têxteis. Rio de Janeiro: Senai/Cetiqt, 1995.

NISHIMURA, Maicon Douglas Livramento; VERGARA, Lizandra Garcia Lupi; GONTIJO, Leila Amaral. Modelagem do vestuário a partir das percepções dos professores em Santa Catarina. DAPesquisa, Florianópolis, v. 12, n. 18, p. 68-78, 8 maio 2017. Disponível em: http://bit.ly/3bOLo38. Acesso em: 19 jan. 2021.

OLIVETE, Ana Luiza; PEREIRA, Paula Virgínia de Britto Lopes; ARRUDA, Káthia Oliveira. Técnicas de modelagem e costura feminina. 2. ed. Brasília: LK Editora, 2010.

POCl, Bárbara Valle; CARVALHO, Cristiane de S. dos Santos de; CUNHA, Glaucia Regina Santos. Corpo feminino: a diversidade das formas brasileiras. In: COLÓQUIO DE MODA, 12., 2016, João Pessoa. Anais [...]. João Pessoa: Associação Brasileira de Estudos e Pesquisas em Moda, 2016. p. 1-12. Disponível em: https://bit.ly/3CRpzKj. Acesso em: 20 ago. 2021.

\section{ROSA, Lucas da. A indústria do vestuário da grande}

Florianópolis: absorção de estudantes do curso superior de moda da Udesc. 2005. 157 f. Dissertação (Mestrado) - Curso de Pós-Graduação em Educação e Cultura, Universidade do Estado de Santa Catarina, Florianópolis, 2005. Disponível em: https://bit.ly/35IwXKt. Acesso em: 05 nov. 2019. 
ROSA, Lucas da. Vestuário Industrializado: uso da ergonomia nas fases de gerência de produto, criação, modelagem e prototipagem. 2011. 175 f. Tese (Doutorado) - Curso de Pós-Graduação em Design, Departamento de Artes e Design, Pontifícia Universidade Católica, Rio de Janeiro, 2011. Disponível em: https://bit.ly/3kDNtzL. Acesso em: 24 fev. 2019.

SANCHES, Maria Celeste de Fátima. 0 projeto do intangível na formação de designers de moda: repensando as estratégias metodológicas para a sintaxe da forma na prática projetual. 2016. 268 f. Tese (Doutorado) - Curso de Arquitetura e Urbanismo/ Diseño, Fabricación y Gestión de Projyectos Industriales, Universidade de São Paulo/Universitat Politècnica de València, São Paulo/Valência, 2016. Disponível em: https://bit.ly/3nOvHLr. Acesso em: 14 jan. 2021.

SANTIAGO, Elida Belquice Araújo; NORONHA, Raquel Gomes; ZANDOMENEGHI, Ana Lucia Alexandre de Oliveira. Metodologias colaborativas do design para modelagem plana do vestuário. Revista de Ensino em Artes, Moda e Design, Florianópolis, v. 4, n. 2, p. 92-108, 1 jun. 2020. Disponível em: http://bit.ly/3o8PgOX. Acesso em: 22 jan. 2021.

SILVA, Edna Maria dos Santos; FRANÇA, Sônia. Modplan: ensino e aprendizagem de modelagem plana por meio de um recurso tecnológico. In: COLÓQUIO DE MODA, 14., 2018, Curitiba. Anais [...]. Curitiba: Associação Brasileira de Estudos e Pesquisas em Moda, 2018. p. 1-13.

SILVEIRA, Icléia et al. A formação dos profissionais do setor de modelagem do vestuário da região do Vale do Itajaí - SC. DAPesquisa, Florianópolis, v. 7, n. 9, p. 552-566, 30 out. 2018. Disponível em: http://bit.ly/38XRxbj. Acesso em: 20 jan. 2021. 
SILVEIRA, Icléia et al. A relação da técnica de moulage com o corpo. In: COLÓQUIO DE MODA, 9., 2013, Fortaleza. Anais [...]. Fortaleza: Universidade Federal do Ceará, 2013. p. 1-12. Disponível em: https://bit.ly/3qjrl0I. Acesso em: 14 jan. 2021.

SILVEIRA, Icléia. Modelo de gestão do

conhecimento: capacitação da modelagem de Vestuário. Florianópolis: Editora UDESC, 2017.

SOUZA, Bárbara Pavei; PEREIRA, Adriana Cardoso. Nem todo trajeto é reto: limites e possibilidades para a sensibilização dos estudantes de design de moda por meio do ensino de modelagem. Revista de Ensino em Artes, Moda e Design, Florianópolis, v. 4, n. 2, p. 11-29, 1 jun. 2020. Disponível em: http://bit.ly/3sC71cP. Acesso em: 18 jan. 2021.

UDESC - Universidade do Estado de Santa Catarina.

Ementas. Florianópolis: Udesc, 2021. Disponível em: https://bit.ly/39zzgRk. Acesso em: 23 jul. 2021.

UNESC - Universidade do Extremo Sul Catarinense.

\section{Curso Superior de Tecnologia em Design de Moda:}

Projeto Pedagógico De Curso (PPC). Criciúma: Unesc, 2016.

Disponível em: https://bit.ly/39yKFkk. Acesso em: 23 jul. 2021. 